\title{
Cellular localization and steroid hormone regulation of mRNA encoding tumour necrosis factor receptor $I$ in mouse uterus
}

\author{
K. F. Roby ${ }^{1}$, N. Laham ${ }^{3}$ and J. S. Hunt ${ }^{1,2 *}$ \\ Departments of ${ }^{1}$ Anatomy and Cell Biology, and ${ }^{2}$ Pathology and Oncology, University of Kansas \\ Medical Center, Kansas City, KS 66160-7400, USA; and ${ }^{3}$ Department of Perinatal Medicine, \\ The Royal Women's Hospital, Carlton, Victoria, Australia 3053
}

\begin{abstract}
Signals transduced by binding of tumour necrosis factor $\alpha$ (TNF) and lymphotoxin $\alpha$ (LT- $\alpha$ ) trimers to high-affinity cell membrane receptors, TNF-RI (p55/p60) and TNF-RII (p75/p80), affect many cell functions. In this study, expression of the gene encoding TNF-RI in uteri of cyclic mice was mapped using in situ hybridization. TNF-RI hybridization signals fluctuated during the cycle. Signal intensity was highest during dioestrus-II, when mRNA encoding TNF-RI was present in endometrial epithelial and stroma cells, as well as in myometrial smooth muscle and connective tissue cells. The ability of oestradiol and progesterone to modulate steady state concentrations of mRNA encoding TNF-RI in uterine cells was assessed by using in situ and northern blot hybridization procedures. Seven days after ovariectomy, low concentrations of mRNA encoding TNF-RI were detected by northern analysis and weak in situ hybridization signals were identified in epithelia and some myometrial connective tissue cells. Administration of oestradiol, progesterone or oestradiol plus progesterone to ovariectomized animals stimulated temporal and cell type-specific changes in steady state concentrations of mRNA encoding TNF-RI that were unique to each hormonal regimen. Maximal induction of mRNA encoding TNF-RI required $24 \mathrm{~h}$ of oestradiol stimulation and $72 \mathrm{~h}$ of progesterone stimulation. In uteri treated with oestradiol plus progesterone, the oestradiol pattern predominated over the progesterone pattern. Thus, multiple cell types in cyclic mouse uteri express the gene encoding TNF-RI, and expression in specific cells is controlled by female steroid hormones.
\end{abstract}

\section{Introduction}

The gene encoding tumour necrosis factor $\alpha$ (TNF) is expressed in rat, human and mouse uteri (reviewed by Hunt, 1993; Terranova $e t$ al., 1995). While the functions of uterine TNF are not fully described, recent experiments suggest that human endometrial TNF may have local autocrine or paracrine effects, assisting in leukocyte migration into the uterus and participating in apoptosis of uterine glands (Tabibzadeh et al., 1993). The observation that expression of the gene encoding TNF is maximal in the mid- to late secretory phases of the human menstrual cycle has prompted the suggestion that TNF, which has cytotoxic properties, has a role in termination of the cycle (Hunt et al, 1992; Hunt, 1993; Philippeaux and Piguet, 1993). Lymphotoxin- $\alpha$ (LT- $\alpha$, TNF- $\beta$ ), a structurally and functionally similar cytokine expressed mainly by lymphocytes, has not been reported in the uteri of cyclic mammals.

TNF and LT- $\alpha$ homotrimers bind with high affinity and specificity to two receptors. TNF-RI (p55/60) and TNF-RII (p75/80) (reviewed by Bazan, 1993; Smith et al., 1994). These receptors are expressed on nearly all cells, although the ratios of type I:type II vary considerably. While the consequences of

*Correspondence and reprint requests.

Received 7 August 1995. signal transduction through each receptor do not appear to be entirely exclusive, there are many instances of individual differences (reviewed by Smith et al., 1994).

The expression of TNF-R in the uteri of cyclic animals has not been studied. Because receptor expression could profoundly influence the autocrine or paracrine effects of TNF and LT $-\alpha$ in uterine cells, we undertook this investigation using northern and in situ hybridization techniques. Subsequently, experiments were done to evaluate hormone effects on steady state concentrations of TNF-RI in the uteri of ovariectomized mice. The results showed clearly that mRNA encoding TNF-RI is differentially expressed in cell types, and that message concentrations in specific types of cells are regulated by oestradiol and progesterone. Thus, subtle adjustments augmenting or negating the effects of TNF may be achieved by ovarian hormones via receptor modulation.

\section{Materials and Methods}

Animals, hormone treatments and tissue collection

Female Swiss mice (2-3 months of age) were purchased from Harlan (Indianapolis, IN). The mice were maintained under a $14 \mathrm{~h}$ light:10 h dark schedule with food and water provided 
ad libitum. Protocols for the handling and care of animals were approved by the University of Kansas Medical Center Institutional Animal Care and Use Committee. At least four animals were used for each stage of the oestrous cycle and for each individual treatment and time point in the ovariectomy and hormone reconstitution experiments. For studies on cyclic mice, stage of the oestrous cycle was determined by daily morphological evaluation of cells in vaginal washes. Mice were used after at least two consecutive cycles. For studies on hormone reconstitution, mice were ovariectomized, irrespective of day of the oestrous cycle, and rested for 1 week, as described by Roby and Hunt (1994). Hormone regimens were initiated 1 week after ovariectomy. Animals were injected s.c. with oestradiol ( $20 \mathrm{ng}$ per mouse), progesterone $(2 \mathrm{mg}$ per mouse), a combination of oestradiol + progesterone (same doses), or vehicle $(0.1 \mathrm{ml}$ sesame oil) once a day for the duration of the experiment. Mice were killed at the time of the first injection or after $1,6,24$ or $72 \mathrm{~h}$. Timing was relative to the first injection. Uteri were either flash-frozen in liquid $\mathrm{N}_{2}$ and stored at $-80^{\circ} \mathrm{C}$ for $\mathrm{RNA}$ isolation or were fixed overnight in freshly prepared, cold $4 \%(\mathrm{w} / \mathrm{v})$ paraformaldehyde for later embedding in paraffin wax as described by Yelavarthi et al. (1991).

\section{Molecular probes}

cDNA encoding TNF-RI was provided by Genetech Inc. (South San Francisco, CA). Digestion of this cDNA with restriction enzymes yielded expected patterns on ethidium bromide-stained agarose gels. A $498 \mathrm{bp}$ fragment of cDNA encoding TNF-RI was subcloned into pSP72 (Roby et al., 1995). For in situ hybridization experiments, the cDNA served as template for polymerase directed synthesis of digoxigeninlabelled antisense and sense cRNA (Genius Labeling Kit: Boehringer Mannheim, Indianapolis, IN) as described by Chen et al. (1993). For northern analysis, the cDNA served as template for polymerase directed synthesis of ${ }^{32} \mathrm{P}$-labelled antisense cRNA (Melton et al., 1984; De et al., 1989). Reagents for the synthesis of probes were purchased from Pharmacia Fine Chemicals (Piscataway, NJ). Restriction enzymes and polymerases were purchased from Promega (Madison, WI). Unless otherwise noted, all other chemicals and reagents were purchased from Sigma Chemical Co. (St Louis, MO).

\section{In situ hybridization procedures}

In situ hybridization experiments were performed as reported by Chen ef al. (1993) and Roby and Hunt (1994) with the following exceptions. Before hybridization, the tissue sections were treated with $1 \mu \mathrm{g}$ proteinase $\mathrm{K} \mathrm{ml}^{-1}$ for $30 \mathrm{~min}$ at $37^{\circ} \mathrm{C}$. After overnight hybridization at $47^{\circ} \mathrm{C}$ in a humidified chamber, the tissue sections were washed extensively, concluding with $0.1 \times \mathrm{SSC}$ (sodium citrate buffer) at $47^{\circ} \mathrm{C}$ for $30 \mathrm{~min}$. Hybridization was detected by first incubating the tissue sections with a biotinylated monoclonal anti-digoxigenin antibody, and then with streptavidin conjugated to alkaline phosphatase. Incubation in a bromochloroindoyl phosphate (BCIP)-containing substrate yielded a brown-to-purple precipitate at the site of TNF-RI cRNA-mRNA hybridization.
The tissue sections were counterstained with methyl green. Uterine tissue sections from four different animals representing each day of the oestrous cycle and each experimental treatment and time were assessed by in situ hybridization, which was repeated at least four times. Signals were assessed by two independent readers and were scored as follows: 0 : none detectable; +/0: detectable but patchy; $t$ : weak signal; ++: moderate signal; +++: high intensity signal. The scores were averaged (Tables $I$ and 2 ).

\section{Northern blot hybridization procedure}

mRNA encoding TNF-RI was detected by northern blot analysis in samples of poly $(A)^{+}$RNA that had been isolated from uteri using the Mini RiboSep Ultra kit (Collaborative Biomedical Products, Bedford, MA) and total RNA from cell lines was then separated by electrophoresis in $1.2 \%(\mathrm{w} / \mathrm{v})$ agarose gels. Spectrophotometer readings taken at $260 \mathrm{~nm}$ and $280 \mathrm{~nm}$ were used to ensure equal loading of the samples. Cell lines used as controls for probe specificity were obtained from the American Type Culture Collection (Gaithersburg. MD) and were maintained in accordance with their instructions. The lines were: RAW264.7 mouse macrophages stimulated with $10 \mu \mathrm{g}$ lipopolysaccharide $\mathrm{ml}^{-1}$ as described by Yelavarthi et al. (1991); EL4 mouse lymphoma cells (TIB29); 7OZ/3 mouse pre-B lymphocytes. EL4 cells express the gene encoding TNF-RI and 7OZ/8 cells express the gene encoding TNF-RII (Goodwin et al., 1991). Pre-hybridization, hybridization $\left(2 \times 10^{6}\right.$ c.p.m. of labelled probe $\left.\mathrm{ml}^{-1}\right)$, and post-hybridization steps were performed as described by Yang et al. (1993).

\section{Results}

\section{Verification of TNF-RI probe specificity}

Northern analysis of mRNA encoding TNF-RI in the cell lines that were used to verify probe specificity are shown (Fig. 1). The mouse macrophage cell line RAW264.7 and the EL4 mouse lymphoma cells (TNF-RI + , TNF-RII - ) contained mRNA encoding TNF-RI, whereas no hybridization signal was detected in $7 \mathrm{OZ} / 3$ pre-B lymphocytes (TNF-RI-, TNF-RII +). Therefore, as expected (Goodwin et al., 1991) and as shown in other studies done in our laboratory (Roby et al., 1995), the cRNA encoding TNF-RI used for northern and in situ hybridization studies did not cross-hybridize with mRNA encoding TNF-RII.

\section{Localization of mRNA encoding TNF-RI in uteri of cyclic mice}

mRNA encoding TNF-RI was detectable on each day of the oestrous cycle (Fig. 2). A hierarchy of signal intensity was observed during cycle progression: dioestrus II $>$ pro-oestrus $>$ oestrus $>$ dioestrus $\mathrm{I}$.

Shifts observed in the cellular locales and intensities of the hybridization signals are summarized (Table 1). During the oestrous phase, signals were mainly confined to the epithelial cells (Fig. 2a). Cells in uteri from animals at dioestrus-I contained little mRNA encoding TNF-RI (Fig. 2b), whereas Downloaded from Bioscientifica.com at 04/26/2023 12:08:21PM 

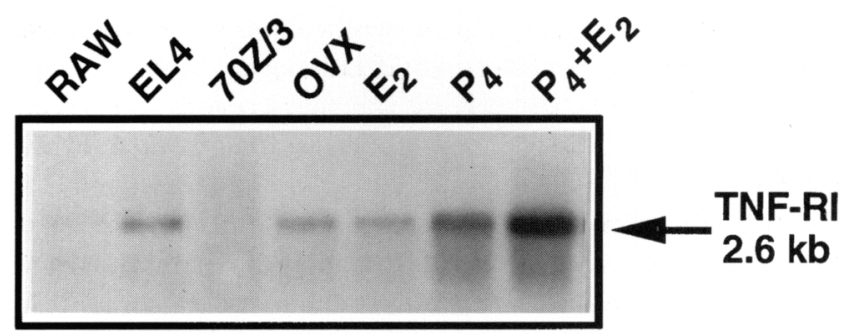

Fig. 1. Northern blot hybridization analysis of mRNA encoding tumour necrosis factor $\alpha$ receptor I (TNF-RI) in cell lines and tissue extracts. From left to right, the lanes contain: RNA from LPSstimulated RAW264.7 mouse macrophages; the lymphoblastoid cell lines, EL4 and $7 \mathrm{OZ} / 3$; and the uteri of ovariectomized mice treated for $24 \mathrm{~h}$ with vehicle $(\mathrm{OVX})$, oestradiol $\left(\mathrm{E}_{2}\right)$, progesterone $\left(\mathrm{P}_{4}\right)$, and oestradiol + progesterone $\left(P_{4}+E_{2}\right)$. RAW264.7, $10 \mu \mathrm{g}$ per lane total RNA; all others, $2 \mu \mathrm{g}$ per lane poly $(\mathrm{A})^{+} \mathrm{RNA}$. Comparisons with a molecular weight ladder (not shown) indicated that mRNA encoding TNF-RI migrated to $2.6 \mathrm{~kb}$.

hybridization signals were extremely strong during dioestrus II (Fig. 2c). At this stage, specific mRNA was localized to luminal and glandular epithelium, endometrial stromal cells, smooth muscle cells and connective tissue cells. The intensity of the hybridization signals diminished markedly during pro-oestrus (Fig. 2d). mRNA encoding TNF-RI remained in the luminal and glandular epithelia, but fewer cells were positive in the endometrial stroma and myometrial cells contained little message.

The effect of ovariectomy and hormone reconstitution on uterine cell expression of the gene encoding TNF-RI

Ovariectomy. Steady state concentrations of mRNA encoding TNF-RI in the uterus 7 days after ovariectomy were low (Fig. 3a). Specific message was confined to endometrial epithelial cells and isolated stromal and myometrial connective tissue cells. Northern blot hybridization also detected mRNA encoding TNF-RI in the uteri of ovariectomized mice (Fig. 1).

Oestradiol. Observations made in time course experiments in which oestradiol was administered to ovariectomized mice, and uteri were harvested at 1, 6, 24 and $72 \mathrm{~h}$, are summarized (Table 2). Message was not detectable in the endometrium $1 \mathrm{~h}$ after oestradiol treatment, but by $6 \mathrm{~h}$ after treatment, specific mRNA was present in epithelial, stromal and myometrial connective tissue cells. Hybridization signal intensities continued to increase in intensity and were highest at $24 \mathrm{~h}$ after treatment (Table 2; Fig. 3b). With the exception that hybridization in the subepithelial stroma was no longer detected, the pattern observed at $6 \mathrm{~h}$ continued to prevail.
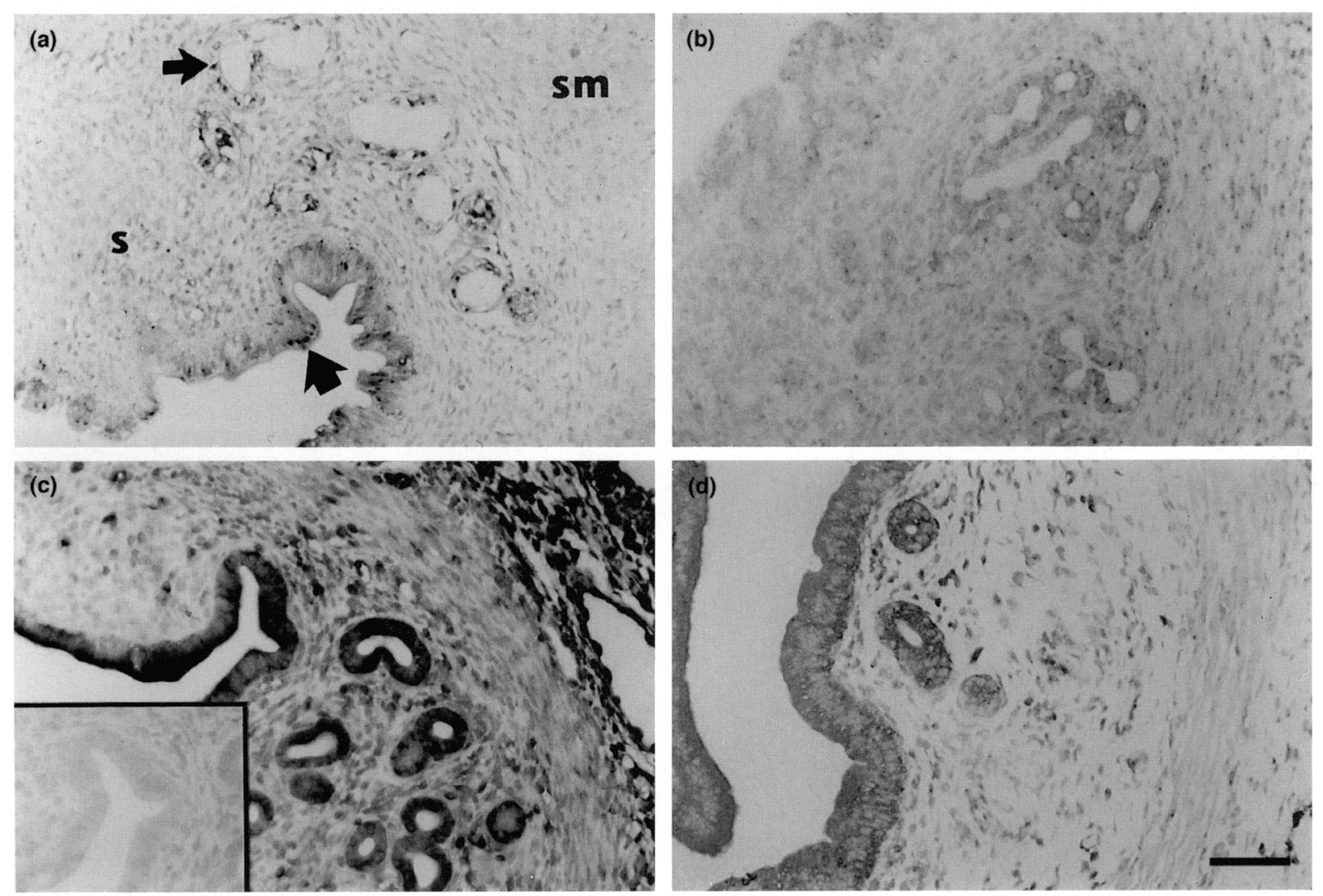

Fig. 2. Identification of mRNA encoding tumour necrosis factor $\alpha$ receptor I (TNF-RI) in samples of uteri from cyclic mice by in situ hybridization, using a 498 bp antisense cRNA specific for TNF-RI. (a) Oestrus. (b) Dioestrus I (metoestrus). (c) Dioestrus II. (d) Pro-oestrus. The sense version of the cRNA encoding TNF-RI served as control and exhibited no hybridization (c, inset). The tissue sections were counterstained with methyl green. Luminal epithelium is identified by a large arrow and glandular epithelium by a small arrow. s: stroma; sm: myometrial smooth muscle. Scale bar represents $50 \mu \mathrm{m}$. 
Table 1. Cellular localization of mRNA encoding tumour necrosis factor $\alpha$ receptor I (TNF-RI) in the uteri of cyclic mice ${ }^{a}$

Site

Oestrus Dioestrus I Dioestrus II Pro-oestrus

$\begin{array}{lcccc}\text { Endometrium } & & & & \\ \text { Epithelium } & + & +10 & +++ & ++ \\ \text { Stroma, proximal } & +10 & 0 & + & +10 \\ \begin{array}{l}\text { Stroma, distal } \\ \text { b }\end{array} & 0 & +10 & + & +10 \\ \begin{array}{l}\text { Myometrium } \\ \text { Connective tissue }\end{array} & 0 & +10 & + & 0 \\ \text { Smooth muscle } & 0 & +10 & +++ & +10\end{array}$

"In situ hybrization signals were scored by two independent readers as follows: 0 : none detectable; +10 : detectable but patchy; + : weak signal; ++ : moderate signal; +++ : high intensity signal. The results were averaged. 'Stroma, proximal refers to subepithelial stroma and stroma; stroma, distal refers to stromal cells subadjacent to the circular muscle.

Seventy-two hours after administration of oestradiol, mRNA encoding TNF-RI had diminished and was detectable only in stromal cells distal to the luminal epithelium and in the myometrial connective tissue. The presence of mRNA encod- ing TNF-RI in uteri $24 \mathrm{~h}$ after administration of oestradiol was confirmed by northern blot hybridization (Fig. 1).

Progesterone. Observations made in time course experiments in which progesterone was administered to ovariectomized mice are summarized (Table 2). In contrast to the patterns observed after administration of oestradiol, where signals were strongest and most extensive at $24 \mathrm{~h}$, peak induction of TNF-RI occurred $72 \mathrm{~h}$ after administration of progesterone. In situ hybridization signals in the uteri of progesterone-treated mice were never as intense as those observed in the uteri of oestradiol-treated mice (Table 2; Fig. 3c). However, as with oestradiol, progesterone had a transient inhibitory effect at $1 \mathrm{~h}$ and, in the uteri of progesterone-treated mice, this persisted for all cell types except epithelial cells at 6 and $24 \mathrm{~h}$. Analysis of RNA from uteri collected $24 \mathrm{~h}$ after administration of progesterone by northern blot also showed the presence of mRNA encoding TNF-RI (Fig. 1).

Oestradiol plus progesterone. The pattern of uterine mRNA encoding TNF-RI observed after administration of oestradiol + progesterone markedly resembled the pattern seen after treatment with oestradiol alone (Table 2). Further, the kinetics of
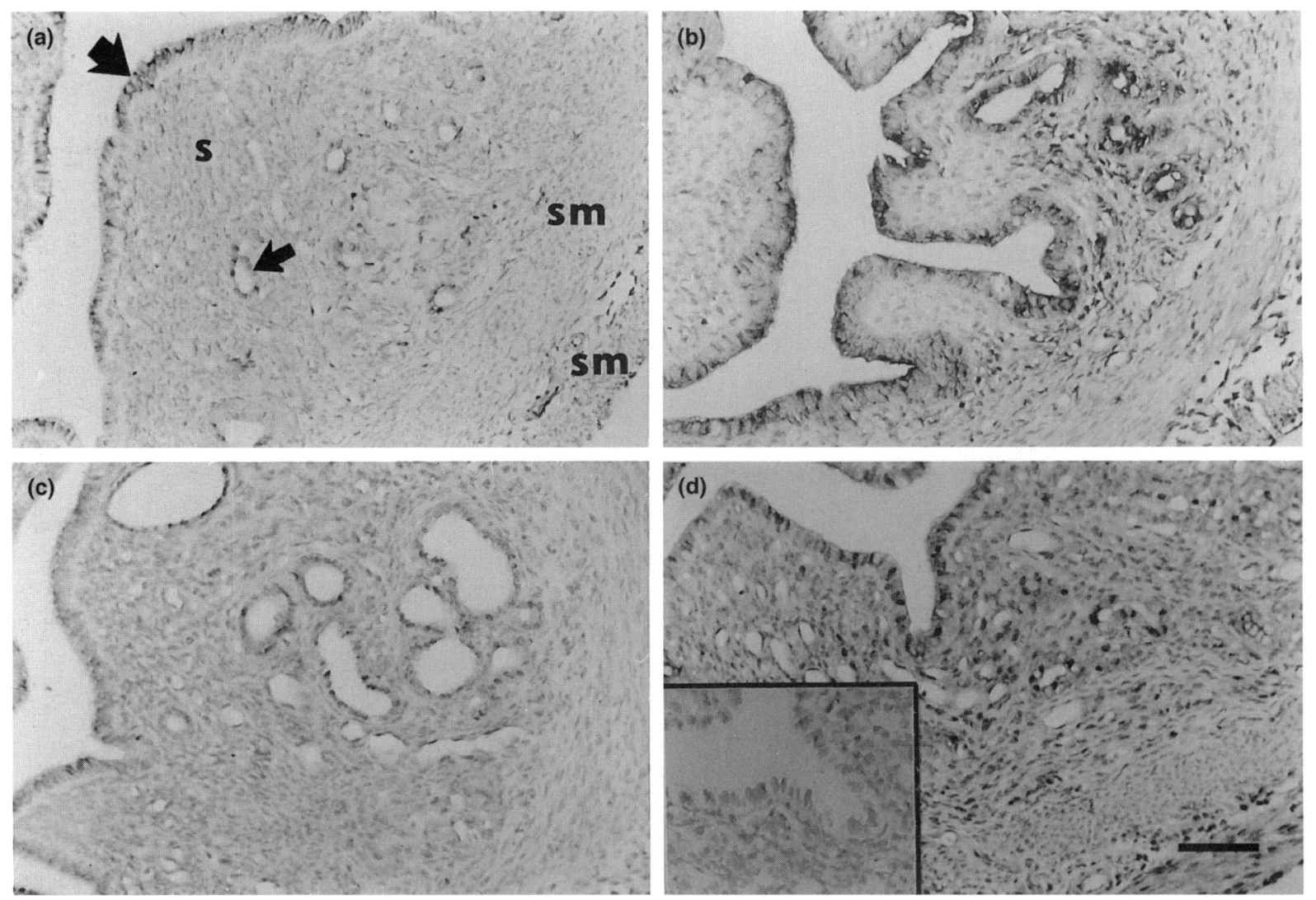

Fig. 3. The effect of ovariectomy and steroid replacement on expression of uterine mRNA encoding tumour necrosis factor receptor I (TNF-RI) assessed by in sifu hybridization $24 \mathrm{~h}$ after hormone treatment. (a) No treatment. (b) Treatment with oestradiol. (c) Treatment with progesterone. (d) Treatment with oestradiol + progesterone. The sense version of the cRNA encoding TNF-RI served as control and exhibited no hybridization ( $\mathrm{d}$, inset). Tissue sections were counterstained with methyl green. Luminal epithelium is identified by a large arrow and glandular epithelium by a small arrow. s: stroma; sm: circular (above) and longitudinal (below) smooth muscle. Scale bar represents $50 \mu \mathrm{m}$. 
Table 2. Expression of mRNA encoding tumour necrosis factor $\alpha$ receptor I (TNF-RI) in ovariectomized, hormonereconstituted mouse uteri by cell type ${ }^{a}$

Time after hormone treatment $(\mathrm{h})$

$\begin{array}{lllll}0 & 1 & 6 & 24 & 72\end{array}$

\begin{tabular}{|c|c|c|c|c|c|}
\hline \multicolumn{6}{|l|}{ Oestradiol } \\
\hline \multicolumn{6}{|l|}{ Endometrium } \\
\hline Epithelium & + & 0 & + & ++ & 0 \\
\hline Stroma, proximal ${ }^{\mathrm{b}}$ & 0 & 0 & + & 0 & 0 \\
\hline Stroma, distal ${ }^{b}$ & 0 & 0 & + & ++ & + \\
\hline \multicolumn{6}{|l|}{ Myometrium } \\
\hline Connective tissue & + & +10 & + & ++ & ++ \\
\hline Smooth muscle & 0 & 0 & 0 & 0 & 0 \\
\hline \multicolumn{6}{|l|}{ Progesterone } \\
\hline \multicolumn{6}{|l|}{ Endometrium } \\
\hline Epithelium & + & 0 & +10 & + & + \\
\hline Stroma, proximal & 0 & 0 & 0 & 0 & + \\
\hline Stroma, distal & 0 & 0 & 0 & 0 & + \\
\hline \multicolumn{6}{|l|}{ Myometrium } \\
\hline Connective tissue & + & +10 & 0 & +10 & + \\
\hline Smooth muscle & 0 & 0 & 0 & 0 & 0 \\
\hline \multicolumn{6}{|c|}{ Oestradiol + progesterone } \\
\hline \multicolumn{6}{|l|}{ Endometrium } \\
\hline Epithelium & + & + & + & ++ & + \\
\hline Stroma, proximal & 0 & 0 & + & 0 & 0 \\
\hline Stroma, distal & 0 & 0 & + & + & +10 \\
\hline \multicolumn{6}{|l|}{ Myometrium } \\
\hline Connective tissue & + & 0 & + & ++ & ++ \\
\hline Smooth muscle & 0 & 0 & 0 & 0 & 0 \\
\hline
\end{tabular}

${ }^{a}$ In situ hybridization signals were scored by two independent readers as follows: 0 : none detectable; +10 : detectable but patchy; + : weak signal; ++ : moderate signal. The results were averaged. 'Stroma, proximal refers to subepithelial stroma and stroma; stroma, distal refers to stromal cells subadjacent to the circular muscle.

TNF-RI induction were similar, with peak expression at $24 \mathrm{~h}$ after treatment. However, mRNA encoding TNF-RI persisted in epithelial cells at $72 \mathrm{~h}$, a pattern that was observed in progesterone- but not oestradiol-treated uterine cells (Table 2). Unexpectedly, oestradiol + progesterone failed to inhibit TNF-RI in epithelial cells at $1 \mathrm{~h}$, despite the ability of both oestradiol and progesterone to accomplish this effect. mRNA encoding TNF-RI was present in the uteri of oestradiol + progesterone-treated mice at $24 \mathrm{~h}$ (Fig. 1).

\section{Discussion}

The results of this study show clearly that cells in the uteri of adult cyclic mice contain mRNA encoding TNF-RI, demonstrate that expression is cell type-specific and dependent upon stage of the oestrous cycle, and provide evidence in support of the postulate that ovarian hormones regulate expression of the gene encoding TNF-RI. The specificity of the cRNA used to identify mRNA encoding TNF-RI by northern and in situ hybridization was verified using receptor-specific cell lines, EL4 and $7 \mathrm{OZ} / 3$, and in situ hybridization controls that used the sense configuration of the cRNA encoding TNF-RI yielded no signals. No attempt was made to correlate the strength of northern hybridization signals and in situ hybridization signals. This is a difficult, perhaps impossible, task in hormone replacement experiments because northern analyses identify the proportion of specific mRNA relative to total cell RNA, which is increased by oestradiol and decreased by progesterone. However, the data were consistent insofar as signals were weak in the uteri of ovariectomized mice and were extremely strong in the uteri of ovariectomized mice restored with oestradiol + progesterone.

The observations reported here are consistent with the postulate that mouse uterine cells exhibit the receptors required for targeting locally or systemically produced TNF. Although the results must be interpreted cautiously because antibodies to mouse TNF-RI have not yet been generated, observations made on human endometria tend to support this idea. Preliminary immunohistochemical studies in our laboratory showed that TNF-RI is indeed present in cyclic human endometrium (H.-L. Chen and J. S. Hunt, unpublished), and recombinant TNF has profound influences on human endometrial cells (Tabibzadeh et al., 1993), indicating that specific receptors are displayed. On balance, therefore, it seems likely that the mRNA encoding TNF-RI in the mouse uterus reported here is processed ultimately into functional TNF-RI. However, many examples of post-transcriptional blocks that prevent protein synthesis have been reported, and further experiments are required to resolve this question.

Luminal and glandular epithelial cells were prominent locales of mRNA encoding TNF-RI. These cells also exhibit TNF and its mRNA during the cycle (Hunt et al., 1993; Roby and Hunt, 1994), suggesting that TNF may serve an autocrine function. In another epithelial cell type, human trophoblast-derived tumour cells, TNF is used as an autocrine growth promoter via the type I TNF-R (Yang et al., 1993), but whether this will turn out also to be the case in normal mouse epithelial cells remains to be seen. Endometrial stromal cells and myometrial connective tissue cells that were positive for TNF-RI may have included macrophages, which are prominent in these locations (reviewed by Hunt and Pollard, 1992; Huang et al., 1995). Northern blot analysis showed that mRNA encoding TNF-RI was present in this lineage. Because bone marrow macrophages use autocrine TNF as a differentiation factor (Myers et al., 1989), the results reported here raise the intriguing possibility that differentiation of tissue macrophages may also involve transient utilization of TNF.

The abundance and cellular distribution of mRNA encoding TNF-RI were strongly dependent upon stage of the oestrous cycle. In situ hybridization signals in all types of uterine cell were much more intense during dioestrus II, when the mouse uterus has been primed with oestrogens and then exposed to high concentrations of progesterone. This is the same stage at which mouse uterine mRNA encoding TNF is highest (Roby and Hunt, 1994), suggesting that during the cycle, similar mechanisms may control both ligand and the TNF-RI.

Oestradiol and progesterone may regulate the biological effects of TNF through differential modulation of TNF synthesis as well as TNF receptor expression. Experiments on cyclic human endometrium first suggested the possibility that uterine TNF is under the control of female steroid hormones (Hunt et al., 1993). Later, hormonal control was verified by using a classic experimental model in which ovariectomized 
mice were restored with hormones (Roby and Hunt, 1994). Use of the same model system in this study showed that steady state concentrations of TNF-RI are regulated by oestradiol and progesterone. Unexpectedly, the TNF-RI patterns identified by in situ hybridization differed markedly from those obtained for TNF. For example, in the TNF experiments progesterone predominated over oestradiol, whereas in the TNF-RI experiments oestradiol predominated over progesterone when the combination of oestradiol + progesterone was administered. Further studies are required to establish the relationships between these patterns and uterine function.

Smooth muscle cells in cyclic uteri contained mRNA encoding TNF-RI that was particularly prominent at dioestrus II, but no message was detected in these cells after ovariectomy and hormone reconstitution. Thus, regulation of TNF-RI in smooth muscle appears to be entirely different from regulation in endometrial epithelial and stromal cells as well as myometrial connective tissue cells, and appears to involve a signal(s) that is not a hormone but is related to the cycle.

In summary, the results of this study show that the gene encoding TNF-RI is expressed in the uteri of cyclic mice, support the concept of individual roles for ovarian steroid hormones in regulating gene expression, and provide evidence for differential regulation by cell type. These findings, in addition to those reported documenting TNF-RI in human placentae and uteri of pregnant mice (Yelavarthi $e t$ al., 1993; Roby et al., 1995), are consistent with the postulate that the TNF-TNF-R system is a major component of the complex uterine growth factor-receptor networks involved in regulation of fertility.

This work was supported by a grant from the National Institutes of Health (HD29156) to J. S. Hunt and by a core grant to the Kansas Mental Retardation Research Center. The authors thank Genetech Inc., South San Francisco, CA, and P. F. Terranova, Dept of Physiology, for the TNF-RI cDNA.

\section{References}

Bazan JF (1993) Emerging families of cytokines and receptors Current Biology 3 603-606

Chen H-L, Marcinkiewicz J, Sancho-Tello M, Hunt IS and Terranova PF (1993) Localization of tumor necrosis factor-alpha messenger ribonucleic acid in the cyclic mouse ovary Biology of Reproduction 48 707-714

De SK, McMaster MT, Dey SK and Andrews GA (1989) Cell-specific metallothionein gene expression in mouse decidua and placenta Development 107 $611-621$
Goodwin RG, Anderson D, Jerzy R, Davis T, Brannan C, Copeland NG, Jenkins NA and Smith CA (1991) Molecular cloning and expression of the type $I$ and type 2 murine receptors for tumor necrosis factor Molecular and Cellular Biology 11 3020-3026

Huang J, Roby KF, Pace JL and Hunt JS (1995) Localization and hormonal regulation of inducible nitric oxide synthase in cycling mouse uterus Journal of Leukocyte Biology 57 27-35

Hunt IS (1993) Expression and regulation of the tumour necrosis factor- $a$ gene in the female reproductive tract Reproduction, Fertility and Development 5 141-153

Hunt JS and Pollard JW (1992) Macrophages in the uterus and placenta. In Current Topics in Microbiology and Immunology, Macrophages and Macrophage Activation pp 39-63 Eds S Gordon and SW Russell. Springer-Verlag, Heidelberg

Hunt IS, Chen H-L, Hu X-L and Tabibzadeh S (1992) Tumor necrosis factor- $\alpha$ mRNA and protein in human endometrium Biology of Reproduction 47 141-147

Hunt JS, Chen H-L, Hu X-L and Pollard JW (1993) Normal distribution of tumor necrosis factor- $\alpha$ messenger ribonucleic acid and protein in virgin and pregnant osteopetrotic (oplop) mice Biology of Reproduction 49 441-452

Melton DA, Krieg PA, Rebegliati MR, Maniatis T, Kinn K and Green MR (1984) Efficient in vitro synthesis of biologically active RNA and RNA hybridization probes from plasmids containing a bacteriophage Sp6 promoter Nucleic Acids Research 12 7035-7057

Myers MJ, Pullen JK, Ghildval N, Eustis-Turf E and Schook LB (1989) Regulation of IL-1 and TNF-alpha expression during the differentiation of bone marrow derived macrophages Journal of Immunology 142 153-160

Philippeaux M-M and Piguet PF (1993) Expression of tumor necrosis factor-a and its mRNA in the endometrial mucosa during the menstrual cycle American Journal of Pathology 143 480-486

Roby KF and Hunt JS (1994) Mouse endometrial tumor necrosis factor- $\alpha$ mRNA and protein: localization and regulation by estradiol and progesterone Endocrinology 135 2780-2789

Roby KF, Laham N, Kroning H, Terranova PF and Hunt JS (1995) Expression and localization of messenger RNA for tumor necrosis factor receptor (TNF-R) I and TNF-RII in pregnant mouse uterus and placenta Endocrine Journal 3 $557-562$

Smith CA, Farrah T and Goodwin RG (1994) The TNF receptor superfamily of cellular and viral proteins: activation, costimulation, and death Cell $\mathbf{7 6}$ 959-962

Tabibzadeh S, Kong QF and Sun XZ (1993) Regulatory roles of TNF- $\alpha$ on transepithelial migration of leukocytes and epithelial dyscohesion Endocrine Journal 1 417-425

Terranova PF, Hunter VJ, Roby KF and Hunt JS (1995) Tumor necrosis factor- $\alpha$ in the female reproductive tract Proceedings of the Society for Experimental Biology and Medicine 209 325-342

Yang Y, Yelavarthi KK, Chen H-L, Pace JL, Terranova PF and Hunt JS (1993) Molecular, biochemical and functional characteristics of tumor necrosis factor- $u$ produced by human placental cytotrophoblastic cells journal of Immunology 150 5614-5624

Yelavarthi KK and Hunt JS (1993) Analysis of p60 and p80 tumor necrosis factor- $\alpha \mathrm{mRNA}$ and protein in human placentas American Journal of Pathology 143 1131-1141

Yelavarthi KK, Chen H-L, Yang Y, Fishback JL, Cowley BD and Hunt JS (1991) Tumor necrosis factor-alpha mRNA and protein in rat uterine and placental cells Journal of Immunology 146 3840-3848 